\title{
Tuberculosis screening at the Sainte-Anne Hospital in Paris - results of first and second IGRA
}

\author{
Albert Nienhaus ${ }^{1,2,4^{*}}$, Paul-Kenneth Gariepy ${ }^{3}$, Catherine Trouve ${ }^{3}$, Christiane Lhaumet ${ }^{3}$, Jean Toureau ${ }^{3}$ \\ and Claudia Peters ${ }^{1}$
}

\begin{abstract}
Introduction: Healthcare workers (HCWs) are exposed to Mycobacterium tuberculosis (MTB) and therefore are screened for tuberculosis (TB). Results of TB screenings with the Interferon- $\gamma$ Release Assay (IGRA) in a French psychiatric hospital without a TB ward are described.
\end{abstract}

Methods: At the Sainte-Anne Hospital, a referral centre for psychiatric patients throughout the municipal region of Paris, IGRA screening is performed during pre-employment and general health examination or after potential contact to MTB. The QuantiFERON Gold in tube (QFT) is used and data on TB history are assessed in a standardized manner.

Results: Between August 2008 und August 2013 in total 1.192 HCWs were tested and the QFT was positive in 265 (22.2\%). Probability of a positive QFT increased with age. A second QFT was performed in $144 \mathrm{HCWs}$ with a positive QFT and 53 (36.8\%) HCWs had a reversion. With a positive QFT close to the cut-off (e.g. 0.35-0.7 IU/ml) the odds ratio for a reversion was 4.6 compared to an INF- $\gamma$ concentration of $\geq 3.0 \mathrm{IU} / \mathrm{ml}$. Probability of reversion was not influenced by preventive chemotherapy, which was completed by 28 (19.4\%) HCWs with a positive QFT. No active TB was detected.

Conclusion: Prevalence of positive IGRA is high in French HCWs as is the number of reversions in IGRA. Reversion rate is particularly high around the cut-off of the IGRA. A borderline zone will therefore reduce the influence of test variability.

Keywords: Tuberculosis, Healthcare workers, Interferon-gamma release assay, Reversion

\section{Introduction}

The risk of contracting tuberculosis (TB) is increased in healthcare workers' (HCWs) [1-3]. TB screening for $\mathrm{HCWs}$ is therefore considered a cornerstone for preventing TB in hospitals [4]. Until now, TB screening was performed using a tuberculin skin test (TST), which has several weaknesses the most important being cross reactivity with BCG vaccination and booster phenomena due to intradermal application. The interferon-gamma release assays (IGRA) are a promising tool to overcome these problems [5-7].

\footnotetext{
* Correspondence: a.nienhaus@uke.de

${ }^{1}$ Center of Excellence for Epidemiology and Health Services Research for Healthcare Professionals (CVcare), University Medical Center Hamburg-Eppendorf (UKE), Hamburg, Germany

${ }^{2}$ Principles of Prevention and Rehabilitation Department (GPR), Institute for Statutory Accident Insurance and Prevention in the Health and Welfare Services (BGW), Hamburg, Germany

Full list of author information is available at the end of the article
}

Because IGRA use antigens specific to Mycobacterium tuberculosis they do not show cross reactivity with BCG vaccination and most non-tuberculosis mycobacteria. As IGRA are in vitro tests the problem of boosting in serial testing is circumvented. IGRA correlate better than TST with exposure to infectious patients [8]. Furthermore, in low incidence countries IGRA have a higher predictive value for disease progression [9-11]. Therefore IGRA are likely to improve both the effectiveness and the efficiency of HCWs screening [12]. However, interpretation of IGRA in the serial testing of HCWs remains to be clarified and a consensus needs to be found as the reversion rate in positive IGRA seems to be high [7,13-17]. The reversion rate depends on the quantitative result of the positive first IGRA. Around the cut-off the reversion rate is particularly high and the clinical importance of this observation is not jet well understood. Do they reflect transient infection, 
good control of the infection with no further stimulation of the immune system or just variability by chance [5]? So far we do not have the answer to this question. However it is questionable whether HCWs with a positive but low result in the IGRA should receive preventive treatment or whether they should be retested before a decision is made $[15,17]$.

In France the incidence of $\mathrm{TB}$ is low (8.9 cases per 100,000 in the year 2007), however the variability of the incidence rate is high. In the region of Paris the incidence rate is as high as $18.4 / 100,000$. Therefore TB prevention is a public health priority in France [18]. Special focus is given to nosocomial infections and the screening of HCWs [19,20]. Since 2007 the French Health Authority has recommended the use of IGRA for these screenings. Published data concerning the results of TB-screenings with IGRA are available from four studies, reporting prevalence rates of positive IGRA from $12 \%$ to $32 \%$ while a TST $\geq 10 \mathrm{~mm}$ was observed in $43 \%$ to $70 \%$ of HCWs [21-24]. However data on reversions in IGRA are still sparse as only one French study covered this subject [24].

At the Sainte-Anne Hospital in Paris TB screening of HCWs with IGRA was started in 2008 and those HCWs with a positive IGRA were offered retesting. Therefore the prevalence of positive IGRA and the reversion rate of positive IGRA can be described.

\section{Method}

The population of this prospective study includes all workers at the Sainte-Anne Hospital in Paris who participated in TB screening between August 2008 and August 2013 due to pre-employment screening, general occupational health $(\mathrm{OH})$ examination or contact with infectious TB patients or materials, and on whom an IGRA was performed. In contact tracings the screening was performed 8 weeks after last contact. The Sainte-Anne Hospital specializes in psychiatry and it is a referral centre for psychiatric patients throughout the municipal region of Paris. The hospital has no TB ward.

Results of the TB screening were assessed in a standardized database. BCG vaccination for all new-borns was mandatory in France until 2008 [19]. Therefore it was assumed that all HCWs were vaccinated, no data on BCG vaccination was considered in this analysis. The TST results in history were assessed from the individual files of the HCWs or by interview. No simultaneous testing with IGRA and TST was performed. All HCWs with a first positive IGRA were retested within 3 months. Only if the second IGRA was positive, too, the respective HCWs was referred to a specialist for consultation concerning preventive chemotherapy of latent TB infection (LTBI).

For the IGRA, the QuantiFERON ${ }^{\circ}$-TB Gold In-Tube Assay (QIAGEN, Cellestis) (QFT) was administered in accordance with the manufacturer's instructions. As the study used anonymous data generated in the scope of routine $\mathrm{OH}$ examinations no approval of an ethics committee was needed.

\section{Statistical analysis}

Chi-square tests were used for categorical data. Adjusted odds ratios (OR) and 95\% confidence intervals (CI) were calculated for putative predictive variables using conditional logistic regression. Model building was performed backwards using the change criteria for variable selection.

\section{Results}

The study population comprises $1.192 \mathrm{HCW}$. The study population is described in Table 1 . In total 265 (22.2\%) of the HCWs were positive in IGRA (Figure 1). No difference was observed between male and female HCWs concerning IGRA results (Table 2). Prevalence of positive IGRA increased with age, if the very young age group ( $<20$ years) is disregarded. No difference was observed regarding the reason for the test, general screening or pre-employment screening. A second IGRA was performed in $144 \mathrm{HCWs}$ with a positive IGRA (55.5\%) and a negative second IGRA was observed in $53 \mathrm{HCWs} \mathrm{(36.8 \% ).} \mathrm{The} \mathrm{re-}$ sults of a TST in history were documented for $195 \mathrm{HCWs}$ (16.4\%). The TST was below $10 \mathrm{~mm}$ in $32.8 \%$ and at least

Table 1 Study population $(n=1.192)$

\begin{tabular}{lcc}
\hline & N & \% \\
\hline Female & 810 & 68.0 \\
Male & 382 & 32.0 \\
Age in years & & \\
$\quad<20$ & 15 & 1.3 \\
$20-<25$ & 248 & 20.8 \\
$25-<30$ & 209 & 17.5 \\
$30-<40$ & 285 & 23.9 \\
$40-<50$ & 204 & 17.1 \\
$50-<60$ & 181 & 15.2 \\
$60+$ & 50 & 4.2 \\
Reason for examination & & \\
General OH examination & 393 & 33.0 \\
Preemployment screening & 769 & 64.5 \\
Contact tracing & 30 & 2.5 \\
First QFT & & \\
Negative & 927 & 77.8 \\
Positive & 265 & 22.2 \\
TST result known & 195 & 16.4 \\
Second QFT performed & 144 & \\
Reversion in IGRA & 53 & \\
\hline
\end{tabular}

*out of 144 with a second QFT. 


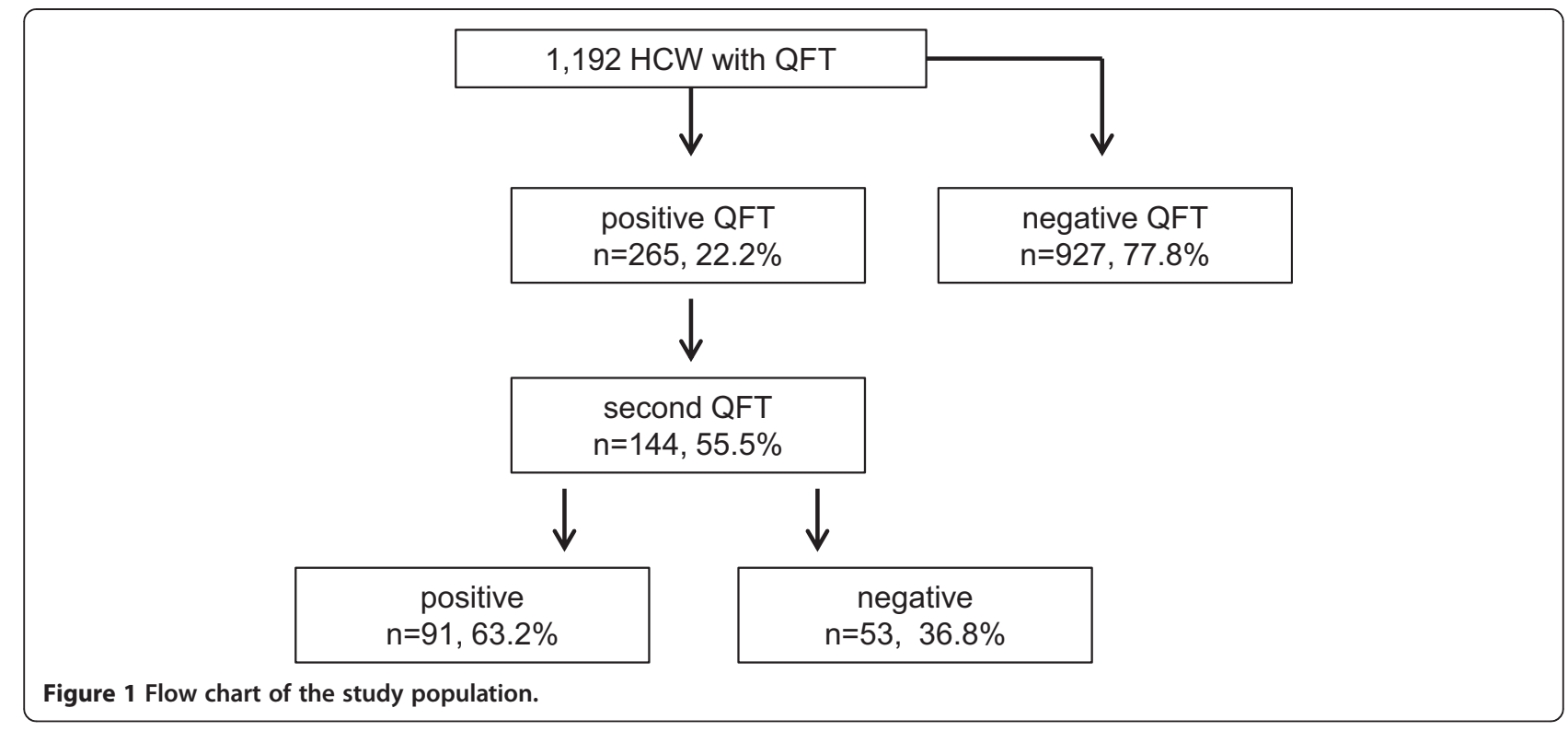

$10 \mathrm{~mm}$ in $67.2 \%$ (Figure 2). The IGRA was more often positive in HCWs with a positive TST (85.5 versus $73.4 \%$, $\mathrm{p}=0.04$ ) than in those with a negative TST in history.

Reversions were more likely in those with a negative TST in history (60.7 versus $31.9 \%, \mathrm{p}=0.008)$. Furthermore reversions were less likely when the IGRA was taken because of a pre-employment screening and more likely when the second IGRA was performed within three months after the first IGRA (OR 2.3; 95\% CI 1.2-6.8) (Table 3). If the concentration of the INF- $\gamma$

Table 2 Risk factors for a positive QFT

\begin{tabular}{|c|c|c|c|c|}
\hline & \multicolumn{2}{|c|}{ QFT positive } & \multirow[b]{2}{*}{ OR } & \multirow[b]{2}{*}{$95 \% \mathrm{C}$} \\
\hline & $\mathbf{N}$ & $\%$ & & \\
\hline Female & 152 & 19.3 & 1 & - \\
\hline Male & 83 & 22.3 & 1.2 & $0.9-1.6$ \\
\hline \multicolumn{5}{|l|}{ Age in years } \\
\hline$<20$ & 4 & 26.7 & 2.2 & $0.7-7.4$ \\
\hline $20-<25$ & 34 & 14.0 & 1 & - \\
\hline $25-<30$ & 33 & 16.1 & 1.2 & $0.7-7.4$ \\
\hline $30-<40$ & 55 & 19.7 & 1.5 & $0.7-2.0$ \\
\hline $40-<50$ & 46 & 22.8 & 1.8 & $1.1-3.0$ \\
\hline $50-<60$ & 48 & 28.2 & 2.4 & $1.5-4.0$ \\
\hline $60+$ & 15 & 31.3 & 2.8 & $1.4-5.7$ \\
\hline \multicolumn{5}{|c|}{ Reason for examination } \\
\hline General $\mathrm{OH}$ exam & 83 & 21.1 & 1 & - \\
\hline Pre-employment & 152 & 19.8 & 1.2 & $0.9-1.7$ \\
\hline Contact tracing* & 30 & 100.0 & - & \\
\hline
\end{tabular}

*30 HCWs, who were examined because of a contact tracing, where excluded from the model as all $30 \mathrm{HCWs}$ had a positive QFT. was between 0.35 and $<0.7 \mathrm{IU} / \mathrm{ml}$ the probability of a reversion was increased (OR 4.6, 95\% CI 1.6-13.4). If the IFN- $\gamma$ concentration was at least $3.0 \mathrm{IU} / \mathrm{ml}$ in the first QFT, probability of a reversion was still $20 \%$. No active TB was diagnosed in the scope of this study.

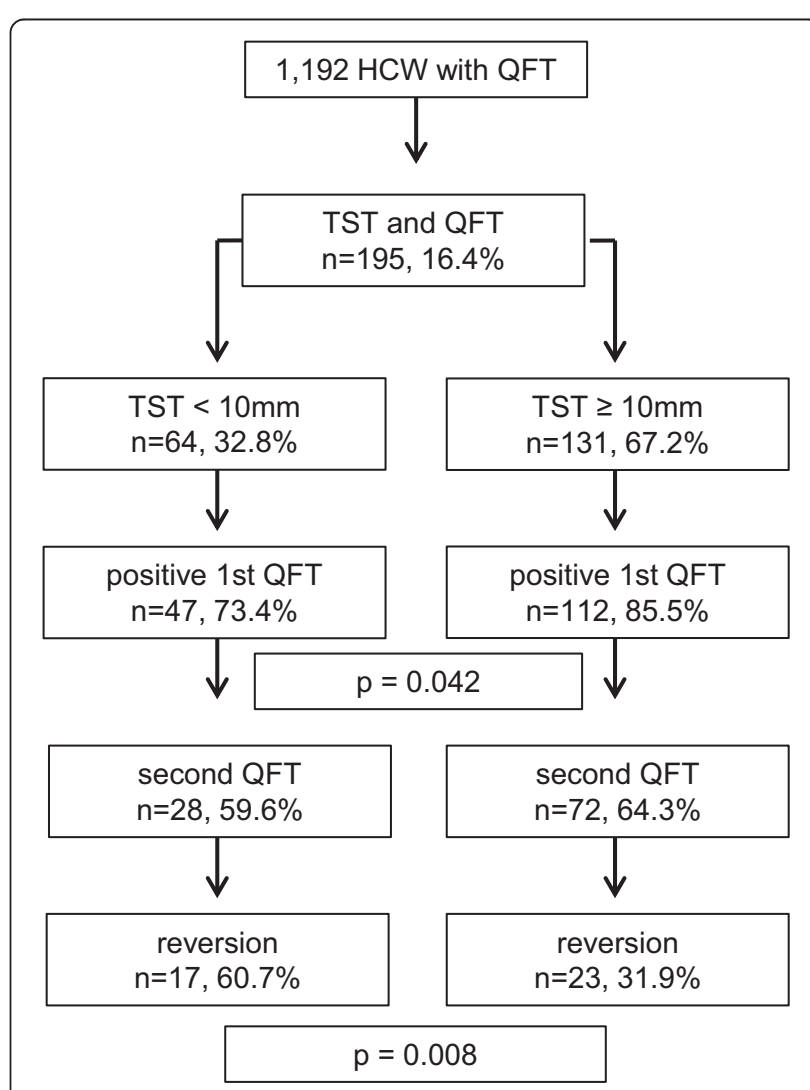

Figure 2 Flow chart of HCWs with a TST in history. 
Table 3 Risk factors for reversion

\begin{tabular}{|c|c|c|c|c|}
\hline \multirow[b]{2}{*}{ Reason for examination } & \multicolumn{2}{|c|}{ QFT reversion } & \multirow[b]{2}{*}{ OR } & \multirow[b]{2}{*}{$95 \% \mathrm{Cl}$} \\
\hline & $\mathrm{N}$ & $\%$ & & \\
\hline General OH exam & 26 & 48.1 & 1 & - \\
\hline Pre-employment & 20 & 26.7 & 0.3 & $0.1-0.9$ \\
\hline Contact tracing & 7 & 46.7 & 1.3 & $0.4-4.6$ \\
\hline \multicolumn{5}{|l|}{ Time between the QFT } \\
\hline$<3$ months & 28 & 45.9 & 2.3 & $1.2-6.8$ \\
\hline $3+$ months & 25 & 30.1 & 1 & - \\
\hline \multicolumn{5}{|l|}{ Concentration of first QFT } \\
\hline $0.35-<0.7 \mathrm{IU} / \mathrm{ml}$ & 20 & 55.6 & 4.6 & $1.6-13.4$ \\
\hline $0.7-<1.0 \mathrm{IU} / \mathrm{ml}$ & 9 & 30.6 & 2.2 & $0.7-7.5$ \\
\hline $1.0-<3.0 \mathrm{IU} / \mathrm{ml}$ & 15 & 39.5 & 2.4 & $0.8-7.1$ \\
\hline $3.0+\mathrm{IU} / \mathrm{ml}$ & 9 & 20.0 & 1 & - \\
\hline \multicolumn{5}{|l|}{ TST in history } \\
\hline $10+m m$ & 23 & 31.9 & 1 & \\
\hline$<10 \mathrm{~mm}$ & 17 & 60.7 & 4.4 & $1.6-12.2$ \\
\hline Unknown, not performed & 13 & 29.5 & 1.3 & $0.5-3.2$ \\
\hline
\end{tabular}

\section{Discussion}

To our knowledge this study is the first to describe a positive association between age and positive IGRA results in French HCWs. Furthermore we observed a high reversion rate of IGRA in HCWs, which was highest when the INF- $\gamma$ concentration of the first IGRA was between $>=0.35$ and $<0.7$ IU and when the second IGRA was repeated within 3 months after the first IGRA. No active TB was diagnosed within the scope of the study and the prevalence of positive IGRA was lower than the prevalence of positive TST in history.

As most French HCWs are BCG vaccinated the discrepancy between TST and IGRA results are well explained. In so far our study corroborates the observations of other studies [23-25]. A high reversion rate of positive IGRA was reported by other studies before [26-33]. As no active TB cases were observed in our study, information for the clinical interpretation of a reversion in IGRA cannot be derived from our data. As the TB risk in our collective seems to be low, it might be safe to conclude that HCWs with a reversion in IGRA will not profit from preventive chemotherapy. In line with this it was proposed that QFTs with an INF- $\gamma$ concentration between 0.35 and $1.11 \mathrm{IU} / \mathrm{ml}$ should be repeated before any other action (X-ray, referral to expert or chemoprevention) is taken in low risk HCWs [15]. Surprisingly, the reversion rate was higher when the IGRA was repeated within three months of the first IGRA. The delay in repeating a first positive IGRA was based on organizational hinders, which should not have influenced the IGRA results.
As only HCWs with positive IGRA results were retested, no information on conversion rates in French HCWs can be derived from our study. In a German low risk group no conversion was observed when a borderline zone for the QFT of 0.2 to $0.7 \mathrm{IU} / \mathrm{ml}$ was applied [34,35]. However, recently several reports were published about higher conversion rates in IGRA than in TST [36-39]. This might indicate that some of the conversions of the IGRA are explained by chance or measurement variability. As IGRA conversion rates are higher when the INF- $\gamma$ of the first IGRA is close to the cut-off, it seems reasonable to introduce a borderline zone for IGRA interpretation in serial testing or to define a minimum increase in INF- $\gamma$ concentration that need to be exceeded for a conversion. In addition it seems reasonable to repeat all first time IGRAs which are positive and to perform $\mathrm{X}$-ray for the exclusion of active TB in the absence of clinical symptoms or preventive chemotherapy only in those HCWs with a confirmed positive IGRA.

\section{Conclusion}

Prevalence of positive IGRA is high in French HCWs as is the number of reversions in IGRA. Reversion rate is particularly high around the cut-off of the IGRA. Before chemoprevention is administered the IGRA should be repeated as HCWs with a reversion in IGRA will most likely not profit from preventive treatment. In HCWs with a reversion in IGRA and no clinical symptoms it seems save not to perform an X-ray. More research is needed in order to better understand the variability of IGRA results. Ultimately a more stable IGRA seems to be desirable.

\section{Competing interests}

All authors declare that they have no competing interests.

\section{Authors' contributions}

AN performed data analysis and wrote the first draft of the manuscript. PKG designed the study, was involved in data collection and made valuable contributions to the manuscript. CT, CL, JT were involved in data collection and made valuable contributions to the manuscript. PC was involved in data analysis and made valuable contributions to the manuscript. All authors read and approved the final manuscript.

\section{Author details}

${ }^{1}$ Center of Excellence for Epidemiology and Health Services Research for Healthcare Professionals (CVcare), University Medical Center

Hamburg-Eppendorf (UKE), Hamburg, Germany. ${ }^{2}$ Principles of Prevention and Rehabilitation Department (GPR), Institute for Statutory Accident Insurance and Prevention in the Health and Welfare Services (BGW), Hamburg, Germany. ${ }^{3}$ Department of Occupational Safety and Health, Sainte-Anne Hospital, Paris, France. ${ }^{4}$ Institute for Health Service Research in Dermatology and Nursing, University Medical Center Hamburg-Eppendorf, Martinistrasse 52, 20246 Hamburg, Germany.

Received: 2 April 2014 Accepted: 2 July 2014

Published: 8 July 2014

\section{References}

1. Baussano I, Nunn P, Williams B, Pivetta E, Bugiani M, Scano F: Tuberculosis among health care workers. Emerg Infect Dis 2011, 17(3):488-494. 
2. Menzies $D$, Joshi R, Pai M: Risk of tuberculosis infection and disease associated with work in health care settings. Int J Tuberc Lung Dis 2007, 11(6):593-605

3. Seidler A, Nienhaus A, Diel R: Review of epidemiological studies on the occupational risk of tuberculosis in low-incidence areas. Respiration 2005, 72(4):431-446.

4. Jensen PA, Lambert LA, lademarco MF, Ridzon R: Guidelines for preventing the transmission of Mycobacterium tuberculosis in health-care settings, 2005. MMWR Recomm Rep 2005, 54:1-141.

5. Andersen $P$, Doherty TM, Pai M, Weldingh $\mathrm{K}$ : The prognosis of latent tuberculosis: can disease be predicted? Trends Mol Med 2007, 13:175-182.

6. Pai M, Zwerling A, Menzies D: Systematic review: T-cell based assays for the diagnosis of latent tuberculosis infection: an update. Ann Intern Med 2008, 149:177-184.

7. Zwerling A, van denHof S, Scholten J, Cobelens F, Menzies D, Pai M: Interferon-gamma release assays for tuberculosis screening of healthcare workers: a systematic review. Thorax 2012, 67:62-70.

8. Diel R, Goletti D, Ferrara G, Bothamley G, Cirillo D, Kampmann B, Lange C, Losi M, Markova R, Migliori GB, Nienhaus A, Ruhwald M, Wagner D, Zellweger $J P$, Huitric E, Sandgren A, Manissero D: Interferon-gamma release assays for the diagnosis of latent Mycobacterium tuberculosis infection: a systematic review and meta-analysis. Eur Respir J 2011, 37(1):88-99.

9. Torres Costa J, Silva R, Ringshausen F, Nienhaus A: Screening for tuberculosis and prediction of disease in Portuguese healthcare workers. J Occup Med Toxicol 2011, 6(1):19.

10. Diel R, Loddenkemper R, Niemann S, Meywald-Walter, Nienhaus A: Negative and positive predictive value of a whole-blood interferon- $\gamma$ release assays for developing active tuberculosis - An Update. Am J Respir Crit Care Med 2011, 183:88-95.

11. Diel R, Loddenkemper $R$, Nienhaus A: Predictive value of interferon-gamma release assays and tuberculin skin testing for predicting progression from latent TB infection to disease state: a meta-analysis. Chest 2012, 142(1):1-13.

12. Nienhaus A, Schablon A, Costa JT, Diel R: Systematic review of cost and cost-effectiveness of different TB-screening strategies. BMC Health Serv Res 2011, 11:247.

13. Ringshausen FC, Schablon A, Nienhaus A: Interferon-gamma release assays for the tuberculosis serial testing of health care workers: a systematic review. J Occup Med Toxicol 2012, 7:6

14. Fong KS, Tomford JW, Teixeira L, Fraser TG, Vanduin D, Yen-Lieberman B, Gordon SM, Miranda C: Challenges of interferon-gamma release assay conversions in serial testing of health care workers in a tuberculosis control program. Chest 2012, 142(1):55-62.

15. Thanassi W, Noda A, Hernandez B, Newell J, Terpeluk P, Marder D, Yesavage JA: Delineating a retesting zone using reciever operation characteristic analysis on serial QuantiFERON tuberculosis test results in US healthcare workers. Pulm Med 2012, 2012:291294.

16. Nienhaus A, Costa JT: Screening for tuberculosis and the use of a borderline zone for the interpretation of the interferon- $\gamma$ release assay (IGRA) in Portuguese healthcare workers. J Occup Med Toxicol 2013, 8(1):1.

17. Nienhaus A, Ringshausen FC, Costa JT, Schablon A, Triopdi D: IFN- $\gamma$ release assay versus tuberculin skin test for monitoring TB infection in healthcare workers. Expert Rev Anti Infect Ther 2013, 11(1):37-48.

18. Migueres B, Carbonne A, Abiteboul D, Poirier C, Bouvet E, Astagneau P: Tuberculosis among healthcare workers in Northern France (2002-2007): descriptive analysis of notified cases and contact tracing. Med Mal Infect 2010, 40:524-529.

19. Che D, Lefebvre N, Antoun F, Fraisse P, Depinoy M, Antoine D, Farge D, Paty MC: Tuberculosis in France: new challenges for the practitioners. Rev Med Interne 2009, 30:142-149.

20. French guidelines for TB screening in HCWs: Groupe de Travail du Conseil Supérieur d'Hygiène Publique: Investigations à conduire autour d'un cas de tuberculose-maladie ou tuberculose-infection récente. Revue des Maladies Infectieuses 2004, 34:391-396.

21. Herrmann JL, Simonney N, Bergeron A, Ducreux-Adolphe N, Porcher R, Rouveau M, Allez M, Leportier M, Tazi A, Lemann M, Lagrange PH: INFY and antibody responses among French nurses during a tuberculosis contact tracing investigation. Pathol Biol 2009, 57:e49-e53.

22. Faibis F, Castelain D, Moreau MC, Tellier J, Dekimeche A, Ittah-Desmeulles H, Fiacre A, Demachy MC: Prevalence of latent tuberculosis infection among health care workers from the emergency department of Meaux hospital using an interferon gamma release assay. Presse Med 2011, 40:e516-e520.
23. Tripodi D, Brunet-Court, Nael V, Audrain M, Chailleux E, Germaud P, Naudin F, Muller JY, Bourrut-Lacouture M, Durand-Perdriel MH, Gordeeff C, Guillaumin G, Houdebine M, Raffi F, Boutoille D, Biron C, Potel G, Roedlich C, Geraut C, Schablon A, Nienhaus A: Evaluation of the tuberculin skin test and the interferon-gamma release assay for TB screening in French healthcare workers. J Occup Med Toxicol 2009, 4:30.

24. Moucaut A, Nienhaus A, Courtois B, Nael V, Longuenesse C, Ripault B, Rucay $P$, Moisan S, Roquelaure $Y$, Tripodi D: The effect of introducing IGRA to screen French healthcare workers for tuberculosis and potential conclusions for the work organisation. J Occup Med Toxicol 2013, 8(1):12.

25. Nienhaus A, Schablon A, Le Bâcle C, Siano B, Diel R: Evaluation of the Interferon-gamma release assay in healthcare workers. Int Arch Occup Enviro Health 2008, 81:295-300.

26. Torres CJ, Sa R, Cardoso MJ, Silva R, Ferreira J, Ribeiro C, Miranda M, Placido $J$, Nienhaus A: Tuberculosis screening in Portuguese healthcare workers using the tuberculin skin test and the interferon-gamma release assay. Eur Respir J 2009, 34(6):1423-1428.

27. Rafiza S, Rampal KG: Serial testing of Malaysian health care workers with QuantiFERON ${ }^{\circledR}-T B$ Gold In-Tube. Int Tuberc Lung Dis 2012, 16(2):163-168.

28. Schablon A, Harling M, Diel R, Nienhaus A: Risk of latent TB infection in individuals employed in the healthcare sector in Germany: a multicentre prevalence study. BMC Infect Dis 2010, 10:107.

29. Pai M, Joshi R, Dogra S, Mendiratta DK, Narang P, Kalantri S, Reingold AL, Colford JM Jr, Riley LW, Menzies D: Serial testing of health care workers for tuberculosis using interferon-gamma assay. Am J Respir Crit Care Med 2006, 174:349-355.

30. Pai M, Elwood K: Interferon-gamma release assays for screening of health care workers in low tuberculosis incidence settings: Dynamic patterns and interpretational challenges. Can Respir J 2012, 19:81-83.

31. Ringshausen FC, Nienhaus A, Torres CJ, Knoop H, Schlosser S, Schultze-Werninghaus G, Rohde G: Within-subject Variability of Mycobacterium-tuberculosis-specific interferon-gamma responses in German health care workers. Clin Vaccine Immunol 2011, 18(7):1176-1182.

32. Schablon A, Harling M, Diel R, Ringshausen FC, Torres Costa J, Nienhaus A: Serial testing with an interferon-gamma release assay in German healthcare workers. GMS Krankenhhyg Interdiszip 2010, 5:1-6.

33. Torres Costa J, Silva R, Sa R, Cardoso MJ, Nienhaus A: Serial testing with the interferon-gamma release assay in Portuguese healthcare workers. Int Arch Occup Enviro Health 2011, 84(4):461-469.

34. Schablon A, Diel R, Diner G, Anske U, Pankow W, Ringshausen FC, Nienhaus A: Specificity of a whole blood IGRA in German nursing students. BMC Infect Dis 2011, 11:245.

35. Schablon A, Peters C, Diel R, Diner G, Anskr U, Pankow W, Ringshausen FC, Nienhaus A: Serial IGRA testing of trainees in the healthcare sector in a country with low incidence for tuberculosis - a prospective cohort study. GMS Hyg Infect Control 2013, 8(2):1-5.

36. Zwerling A, Benedetti A, Cojocariu M, Mclntosh F, Pietrangelo F, Behr MA, Schwartzman K, Menzies D, Pai M: Repeat IGRA testing in Canadian health workers: conversion or unexplained variability? Plos One 2013 8(1):e54748

37. Joshi M, Monson TP, Joshi A, Woods GL: Interferon gamma release assay conversions and reversions: challenges with serial testing in US healthcare workers. Ann Am Thorac Soc 2014, 11(3):296-302.

38. Dorman SE, Belknap R, Graviss EA, Reves R, Schluger N, Weinfurter P, Wang Y, Cronin W, Hirsch-Moverman Y, Teeter LD, Parker M, Garrett DO, Daley CL: Interferon- $\gamma$ release assays and tuberculin skin testing for diagnosis of latent tuberculosis infection in healthcare workers in the United States. Am J Respir Crit Care Med 2014, 187(1):77-87.

39. Slater ML, Welland G, Pai M, Parsonnet J, Banaei N: Challenges with QuantiFERON-TB Gold assay for large-scale, routine screening of US healthcare workers. Am J Respir Crit Care Med 2013, 188(8):1005-1010.

doi:10.1186/1745-6673-9-24

Cite this article as: Nienhaus et al:: Tuberculosis screening at the SainteAnne Hospital in Paris - results of first and second IGRA. Journal of Occupational Medicine and Toxicology 2014 9:24. 